Bond University

Research Repository

\title{
Survey of paediatric intravenous fluid prescription: Are we safe in what we know and what we do?
}

Keijzers, Gerben; McGrath, Melissa; Bell, Christa

Published in:

EMA - Emergency Medicine Australasia

DOI:

10.1111/j.1742-6723.2011.01503.x

Licence:

Other

Link to output in Bond University research repository.

Recommended citation(APA):

Keijzers, G., McGrath, M., \& Bell, C. (2012). Survey of paediatric intravenous fluid prescription: Are we safe in what we know and what we do? EMA - Emergency Medicine Australasia, 24(1), 86-97.

https://doi.org/10.1111/j.1742-6723.2011.01503.x

\section{General rights}

Copyright and moral rights for the publications made accessible in the public portal are retained by the authors and/or other copyright owners and it is a condition of accessing publications that users recognise and abide by the legal requirements associated with these rights.

For more information, or if you believe that this document breaches copyright, please contact the Bond University research repository coordinator. 


\title{
Paediatric Fluid prescription - a survey of practice in an Australian Tertiary Hospital.
}

\author{
$\underline{\text { M McGrath }}{ }^{1}$, G Keijzers ${ }^{1}$, C Bell \\ 1 The Gold Coast Hospital, 108 Nerang St, Southport, QLD, 4215. melsmcgrath@yahoo.com
}

\section{ABSTRACT}

Aim

Administration of intravenous fluids in our paediatric population is commonplace in hospitals. Over the past ten years there has been an increasing body of evidence relating to the risks associated with this therapy. Of particular concern is the risk of iatrogenic hyponatraemia and its ensuing mortality and morbidity. This study aims to observe and evaluate prescribing habits and workplace behaviours of doctors in our institution with regards to the administration of paediatric intravenous fluids.

\section{Methods}

A prospective, observational study was performed at the Gold Coast Hospital. A convenience sample of 106 doctors from the included specialties completed the study questionnaire (Emergency Department, Paediatrics, Anaesthetics, Intensive care and Surgery). Doctors completed a three part questionnaire that included eight scenarios requiring a fluid calculation and a fluid choice. Data on demographic variables and workplace practices were also collected and doctors were asked to complete some general knowledge questions regarding fluid types, fluid tonicity and hyponatraemia.

\section{Results}

$71 \%$ of questionnaires were returned. $91.4 \%$ of respondents had a method for calculating a fluid bolus although only $60.6 \%$ of these answers were correct. $97.2 \%$ of respondents had a method for calculating paediatric maintenance fluids and $79.6 \%$ had correct answers. The majority of questions that asked for a fluid calculation were answered well although those questions dealing with infants and the question regarding a fluid deficit were answered poorly. Subgroup analyses revealed that senior doctors performed better than junior doctors, Emergency department doctors and those working in the field of paediatrics outperformed the other specialities. Similarly doctors with previous paediatric experience and those that frequently prescribed intravenous fluids also had significantly higher scores.

The overall standard of general knowledge in regards to hyponatraemia and tonicity of fluid solutions was high in all groups but this knowledge was not reflected in their fluid prescriptions, especially for those most at risk of iatrogenic hyponatraemia.

\section{Conclusions}

The majority of doctors in this Australian Tertiary hospital have a correct method for prescribing bolus and maintenance fluid rates. As their experience and expertise increase in this area so too does their

This is the peer reviewed version of the following article: Keijzers, G., McGrath, M., \& Bell, C. (2012).

Survey of paediatric intravenous fluid prescription: Are we safe in what we know and what we do? 
confidence in prescribing intravenous fluids to our paediatric population. There is a need for further education in this area for our junior doctors, as well as a need for the introduction of standardised guidelines for fluid usage so as to ensure patient safety and to reduce the risk of iatrogenic hyponatraemia in our paediatric patients. There is also an argument that use of hypotonic fluid preparations should be restricted to specialist paediatric critical care and transplant units.

\section{Key Words}

Paediatric, intravenous fluid solutions, hyponatraemia, hypotonic fluid, isotonic fluid

\section{INTRODUCTION}

Administration of intravenous fluids to children is common practice in a hospital setting. Children receive fluids for a variety of reasons and with the development of accurate modern pumps, delivery rates of these fluids can be controlled and are deemed to be safe (1).

However there have been many instances of serious morbidity and mortality in previously healthy children associated with the administration of intravenous fluids. The main reason for this has been iatrogenic hyponatraemia $(1)(2)(3,4)$ as a result of using incorrect fluid types (hypotonic fluids) and fluid delivery rates. Moreover prescribers and their traditional fluid calculations have not taken into account the effects of antidiuretic hormone (ADH), the secretion of which can be increased by multiple factors encountered in an acute illness or in the perioperative period and lead to hyponatremia as well. $(5),(4,6)$

Intravenous fluids have been used in children for over 50 years. The fundamentals in paediatric fluid prescription were outlined in the 1957 landmark paper by Holliday and Segar (7). They proposed a simple formula to determine the type of maintenance fluid needed in children. This formula took into account their caloric expenditure according to their weights and insensible and urinary water losses. They estimated metabolic requirement for patients at bed rest and proposed that under normal conditions $1 \mathrm{ml}$ of water is required to metabolise $1 \mathrm{kcal}$ and since calorie and water consumption were considered equal, this was the basis of the well known and widely used, "4/ 2/ 1" rule. (See Table 1)

Table 1 Hourly (4/2/1 rule) and daily maintenance fluids according to child's weight

\begin{tabular}{|l|l|l|}
\hline Weight & Hourly fluid requirements & Daily fluid requirement \\
\hline$<10 \mathrm{~kg}$ & $4 \mathrm{~mL} / \mathrm{kg}$ & $100 \mathrm{ml} / \mathrm{kg}$ \\
\hline $10-20 \mathrm{~kg}$ & $40 \mathrm{ml}+2 \mathrm{ml} / \mathrm{kg}$ above $10 \mathrm{~kg}$ & $1000 \mathrm{ml}+50 \mathrm{ml} / \mathrm{kg} \mathrm{above} 10 \mathrm{~kg}$ \\
\hline$>20 \mathrm{~kg}$ & & $1500 \mathrm{ml}+25 \mathrm{ml} / \mathrm{kg}$ above $20 \mathrm{~kg}$ \\
& $60 \mathrm{ml}+1 \mathrm{ml} / \mathrm{kg}$ above $20 \mathrm{~kg}$ & \\
\hline
\end{tabular}

This is the peer reviewed version of the following article: Keijzers, G., McGrath, M., \& Bell, C. (2012).

Survey of paediatric intravenous fluid prescription: Are we safe in what we know and what we do? 
They based their electrolyte needs for children on the composition of human and cow's milk which transposed into a figure of $3 \mathrm{mmol} / \mathrm{kg}$ of sodium and $2 \mathrm{mmol} / \mathrm{kg}$ of potassium. (8)

This formula-based approach translated into the widespread use of hypotonic maintenance fluid solutions which has largely remained unchanged (9). Holliday and Segar's formula has resulted in ongoing hypotonic fluid use for maintenance fluid regimens as their "ideal "solution proposed was $4 \%$ dextrose/ $0.18 \%$ saline.

However, there are 2 main flaws associated with this approach, both leading to overestimation of energy requirement. The use of weight alone to calculate energy expenditure (as compared to using body surface area) will often overestimate caloric requirements and secondly energy expenditure in healthy children (on whom these models are based) is vastly different to that of unwell children (who may be catabolic, inactive or pharmacologically sedated). This may again overestimate energy needs. (3)

Holliday and Segar have also been generous in their estimation of sensible and insensible fluid losses. Estimates of urinary water losses were based on the observation that patients with dilute urine received too much water and conversely, those with concentrated urine received too little water. Today we realize that this has not taken into account the effect of antidiuretic hormone (ADH).

This is of concern as there is an increasing body of evidence that shows hypotonic maintenance fluid solutions can contribute to potentially lethal hyponatraemia in conjunction with an increase in ADH production that is seen in hospitalized children. $((10)(11)(12,13)$ (see table 2) Some researchers have postulated that hyponatraemia can develop in up to $30 \%$ of hospitalized patients. (14)

Hyponatraemia is defined as a serum sodium concentration less than $136 \mathrm{mmol} / \mathrm{L}$ with morbidity occurring at levels less than $125 \mathrm{mmol} / \mathrm{L}$. The action of ADH preventing free water excretion as well as a source of electrolyte free water are usually required for its development(2).

Table 2 Clinical Settings of Increased ADH Release in Children

\begin{tabular}{|l|l|}
\hline $\begin{array}{l}\text { Haemodynamic Stimuli for ADH release } \\
\text { (decreased circulating volume) }\end{array}$ & Non haemodynamic Stimuli for ADH release \\
\hline Hypovolaemia & $\begin{array}{l}\text { Central Nervous System disturbances } \\
\text { Eg. Meningitis, encephalitis, intracerebral bleeds, head injury }\end{array}$ \\
\hline Nephrosis & Pneumonia, asthma, bronchiolitis \\
\hline Cirrhosis & Cancer \\
\hline Congestive cardiac failure & Medications eg NSAIDS,steroids, opiates \\
\hline Hypoaldosteronism & Nausea, vomiting, pain, stress, fasting states \\
\hline
\end{tabular}

This is the peer reviewed version of the following article: Keijzers, G., McGrath, M., \& Bell, C. (2012).

Survey of paediatric intravenous fluid prescription: Are we safe in what we know and what we do? 
Although it is widespread practice to use isotonic fluids for restoration (bolus administration) of circulatory volume (15) it is not common practice to use them as maintenance fluids and a myriad of hypotonic solutions still exist in hospitals thereby confounding and confusing practice. Recent surveys have been carried out in the UK in paediatric hospitals, which show the majority of respondents still use hypotonic solutions as their maintenance fluids. $(16,17)$ Compounding this problem is that often these hypotonic fluids are labeled "isotonic". Whilst these solutions may be isosmolar compared to plasma, lack of osmotically active solutes means that they are hypotonic with reference to the cell membrane. (5)

The problem of morbidity and even mortality as a result of hypotonic fluid administration may be caused by either a lack of knowledge with regards to the risk of hypotonic fluid administration or as a result of inappropriate fluid rates due to incorrect calculations, or a combination of both. We wanted to describe the prescribing habits of a diverse group of doctors in our institution to gain an appreciation of their current prescribing practice of paediatric intravenous fluids in a variety of situations. We also wanted to investigate as to whether there was an awareness of the potential for hyponatraemia to develop and if this was considered in their fluid prescriptions.

\section{METHODS}

This was a prospective, observational study, conducted at the Gold Coast Hospital in June 2009.

The study's objective was to observe, describe and evaluate the prescribing ability and practices of doctors in regards to paediatric fluid orders at an Australian tertiary hospital.

150 questionnaires were distributed under doctors who were (potentially) involved with paediatric fluid prescription. The questionnaire aimed to ask question with regards to demographic variables and ascertain the type of fluid prescribed and the rate of fluid administration in a variety of common clinical scenarios. It also aimed to assess some general knowledge concepts associated with hyponatraemia. Scores were attributed to their answers. These scores were then related to their paediatric experience, workplace behaviours and demographics, and the perceived adequacy of their prior education in the development of their prescribing habits.

Approval for the conduct of this study was obtained from the Gold Coast Health Service District Human Research Ethics Committee.

\section{Survey Design}

The questionnaire (Appendix A: Part A, B and C) was created by the principal researchers after review of the published literature using the MeSH headings intravenous fluids, paediatrics, paediatric intravenous fluids, hyponatraemia, hypotonic fluid, isotonic fluid and fluid prescription survey. Both Medline-Ovid and PubMed databases were examined. The bibliographies of retrieved articles were also reviewed.

Part $\mathbf{A}$ of the questionnaire surveyed the demographics and workplace behaviours of the participating doctors. It also examined their experience in paediatrics and if they had undertaken specific paediatric courses such as the Acute Paediatric Life Support (APLS) course.

This is the peer reviewed version of the following article: Keijzers, G., McGrath, M., \& Bell, C. (2012).

Survey of paediatric intravenous fluid prescription: Are we safe in what we know and what we do?

EMA - Emergency Medicine Australasia, 24(1), 86-97, which has been published in final form at https://doi.org/10.1111/j.1742-6723.2011.01503.x. This article may be used for non-commercial purposes in accordance with Wiley Terms and Conditions for Use of Self-Archived Versions 
Participants were asked how frequently they would prescribe fluids for a paediatric population, how often they had been formally tested in this area, how often they double-checked their rates with themselves or with colleagues and how adequate they felt their prior training and education had been in this field .

Part B of the questionnaire involved 10 questions. The first two questions asked the participants to confirm and describe their particular formula for calculating bolus and maintenance fluid rates. The next eight questions related to clinical scenarios that required the participants to perform some simple calculations to assess either a bolus or maintenance rate or a fluid deficit amount. The participants also had to decide upon a particular type of fluid to use. A list of ten fluids were given, all of which at the time of the questionnaire design were in use in our hospital.

The scenarios were all common presentations found in a tertiary referral hospital and the weights in kilograms of the children in the scenarios were supplied so as to provide consistency for the participants.

A "calculation" and "fluid" score was derived depending on the number of correct answers. For calculation scores, the correct answer with a $10 \%$ error margin was deemed correct and the fluid scores took into account that for certain question several of the fluids listed could be marked as correct.

In the questionnaire a total of 9 questions required a calculation for a bolus, deficit or maintenance rate. A correct answer was based on the formula in Table 1, and we coded the answer as 'correct' if the calculation was within $10 \%$ of this correct answer. Unanswered questions were coded as incorrect. A total score was calculated and transformed to a percentage score, called the "Calculation Score".

Similarly the questionnaire required participants to choose a particular type of fluid in 8 of the questions. Unanswered questions were coded as incorrect and the fluids chosen as correct are shown in Table 5. These fluids were deemed to be the most appropriate type of fluid for the scenarios based on the individual children's sodium and glucose requirements. This questionnaire did not address potassium requirements. Again a total score was calculated and transformed into a percentage score, which has been labeled the "Fluid Score".

Part $\mathbf{C}$ of the questionnaire involved ten questions which related to what the principal researchers felt was some core general knowledge questions that covered a broad range of topics when considering hyponatraemia and paediatric fluid prescription.

There were 10 questions and unanswered questions were coded as incorrect. A score out of 10 which was then converted to a percentage score and labeled the "Knowledge Score".

A fourth score was also calculated which combines fluid calculations, fluid types and knowledge and is a score out of 27 which again has been transformed into a percentage score. This is labeled the "Total" score

The questionnaire was pilot-tested in July 2009 on a group of practicing emergency physicians and a paediatrician. After feedback and discussion, minor modifications were made to the initial questionnaire prior to its distribution.

\section{Study Population}

This is the peer reviewed version of the following article: Keijzers, G., McGrath, M., \& Bell, C. (2012).

Survey of paediatric intravenous fluid prescription: Are we safe in what we know and what we do?

EMA - Emergency Medicine Australasia, 24(1), 86-97, which has been published in final form at https://doi.org/10.1111/j.1742-6723.2011.01503.x. This article may be used for non-commercial purposes in accordance with Wiley Terms and Conditions for Use of Self-Archived Versions 
The study was conducted over the two campuses that comprise the Gold Coast Hospital, a tertiary hospital located in south-east Queensland. Gold Coast Hospital is a teaching facility affiliated with the University of Queensland, Griffith University and Bond University. The Southport campus covers all major specialties excluding cardio-thoracic surgery, burns and paediatric/neonatal intensive care. It has 700 beds and a mixed Emergency department which had 64500 presentations in 2008.12325 of these presentations were paediatric and there 3923 paediatric admissions for this period. $85 \%$ of children admitted have intravenous fluid therapy at some stage during their admission.

The Robina campus is located $12 \mathrm{~km}$ from the main campus and is an urban district hospital with 200 beds. It has a general medical, surgical and orthopaedic services as well as a psychiatric facility. It also has a mixed Emergency department which had 42937 presentations in 2008, 8700 of these were paediatric. As there is no paediatric admission unit at the Robina campus all paediatric admissions are transferred to the Southport campus. Most medical staff rotate between the two campuses. Similar to most Australian hospitals, Gold Coast Hospital employs medical staff who are both locally and internationally trained. Gold Coast Hospital is the only public health facility servicing a permanent population of approximately 550000 people, with considerable seasonal variation due to the city's appeal as a tourist and major event destination.

The survey was distributed over a five week period from June to July 2009 to a convenience sample of consultant staff, registrars and residents (Senior House Officers [SHO], Junior House Officers [JHO] and Interns) from the study's included specialties. The specialties chosen were Emergency Medicine, Paediatrics, Anaesthetics, Intensive Care and Surgery (including Orthopaedics). Inclusion criteria inferred experience and interaction with paediatrics in a variety of settings eg, perioperatively, in the Emergency Department, on a general paediatric ward and in the Intensive Care and Special Care Nursery environments. For this reason the specialties of Psychiatry, Medicine and Obstetrics and Gynaecology were excluded. There were no other exclusion criteria.

The surveys were distributed by the researchers at staff handovers, rostered education sessions and lunchtime meetings. They were collected immediately after completion. Prior to the distribution of the survey, the participant information sheet was read aloud by the researcher, and participants had the opportunity to ask questions and participate on a voluntary basis. The survey was anonymous, calculators were permitted, and no time limit was set, although fifteen minutes was suggested as an approximate time-frame within which to complete the questionnaire. Participants were asked not to confer with colleagues on answers.

\section{Statistical Analysis}

Data was collated and stored using Microsoft Excel ${ }^{\mathrm{TM}}$ software. Prior to analysis, all variables were examined through the Statistical Package for the Social Sciences ${ }^{T M}$ (version 17.0) for missing values, outliers and accuracy of data entry.

Several variables were recoded to construct dichotomous variables. Seniority of doctors was divided into junior (Intern / JHO / SHO) doctors, with three or less years in practice, and senior (Registrar / Consultant) doctors with more than 3 years experience.

Paediatric experience was also divided into at least some specific paediatric experience or only medical school/ mixed ED experience. The frequency of fluid calculations was divided into weekly or less than weekly

This is the peer reviewed version of the following article: Keijzers, G., McGrath, M., \& Bell, C. (2012).

Survey of paediatric intravenous fluid prescription: Are we safe in what we know and what we do?

EMA - Emergency Medicine Australasia, 24(1), 86-97, which has been published in final form at https://doi.org/10.1111/j.1742-6723.2011.01503.x. This article may be used for non-commercial purposes in accordance with Wiley Terms and Conditions for Use of Self-Archived Versions 
For continuous variables, such as the mean calculation, fluid, knowledge and total scores, one-way ANOVA and Student's independent t- test were used to test for significant differences in scores between demographic groups. In order to compare the categorical data of several demographic groups, the chisquare test was performed to detect difference in proportions.

An alpha value of less than 0.05 was deemed to be statistically significant

\section{RESULTS}

A total of 150 surveys were distributed. 106 subjects completed the questionnaire resulting in a response rate of $71 \%$. One subject did not complete their gender.

The demographic characteristics and the workplace behaviours in terms of prescribing frequency, formal testing and calculation checking of their intravenous fluid prescriptions of the 106 included subjects are summarised in Table 3. Unanswered questions by the participants or incomplete demographic data has been labeled as missing. Overall there were few missing data, with demographic variables having a maximum of $2.8 \%$ missing $(\mathrm{N}=3)$, and for fluid or calculation questions only two questions had more than $10 \%$ missing (Question 6, 13.2\% missing, $\mathrm{N}=14$ and Question 9, 11.3\% missing, $\mathrm{N}=12$ ).

The majority of the respondents (91.4\%) had a method for calculating a fluid bolus although only $60.6 \%$ of these answers were correct. Similarly nearly all of the subjects (97.2\%) tested had a method of calculating their maintenance fluids and $79.6 \%$ of people were correct in describing this maintenance formula.

The frequency and percentage of correct and incorrect answers for the fluid calculations in the 8 scenarios presented in the questionnaire, are documented in Table 4. The correct fluid choices and the rationale for using the particular fluids are outlined in Table 5.

The majority of the questions regarding the fluid calculations were answered well (ie $>75 \%$ of correct answers). However some questions were answered poorly (Question 6 and question 9).

Question 6 asked respondents to calculate a fluid deficit, a fairly common occurrence in a hospital setting, and only $54.7 \%$ of people were correct in their answer. This translated into their maintenance rate being incorrect $(46.2 \%$ correct) as well as their fluid choice $(48.1 \%$ correct).

Question 9 outlined a scenario whereby a small baby had the potential to develop an over secretion of $\mathrm{ADH}$ in association with her intercurrent illness. Only $17.9 \%$ of responses were correct and only $34.9 \%$ of fluid choices were correct.

Overall the knowledge questions were all done extremely well with the great majority of respondents having a Knowledge score of at least $85 \%$.

\section{Analyses for Scores by Demographic Variable}

As outlined previously a fluid, calculation, knowledge and total score was derived and applied to certain demographic variables. See Table 6.

This is the peer reviewed version of the following article: Keijzers, G., McGrath, M., \& Bell, C. (2012).

Survey of paediatric intravenous fluid prescription: Are we safe in what we know and what we do?

EMA - Emergency Medicine Australasia, 24(1), 86-97, which has been published in final form at https://doi.org/10.1111/j.1742-6723.2011.01503.x. This article may be used for non-commercial purposes in accordance with Wiley Terms and Conditions for Use of Self-Archived Versions 
Men and women had similar total scores $(73.9,95 \% \mathrm{Cl} 68.7-79.0$ vs $.70 .0,95 \% \mathrm{Cl} 63.4-76.6, \mathrm{P}=0.35)$. However, men did score significantly higher than women when comparing calculation alone $(70.9,95 \% \mathrm{Cl}$ $64.9-76.9$ vs. $57.3,95 \% \mathrm{Cl} 48.9-65.7, \mathrm{P}=0.01$ ) The Fluid scores were also similar but men scored slightly higher than the women. Knowledge scores between the two genders were similar, although men trended to score slightly lower than women.

As highlighted in Table 6, there were major differences between the senior doctors and junior doctors. Senior doctors scored significantly higher on the Total score, Calculation score, Fluid score, but not Knowledge score $(90.495 \% \mathrm{Cl} 82.2-98.6$ vs $85.795 \% \mathrm{Cl} 76.9-94.5 \mathrm{P}=0.44)$.

Doctors with previous paediatric experience also scored higher than those with only paediatric experience derived from medical school or from a mixed ED environment. Those with previous paediatric experience had better results in all their scores. However there was only a significant difference in their Calculation score $(71.095 \% \mathrm{Cl} 64.4-76.6$ vs $59.195 \%$ Cl $51.5-66.7 \mathrm{P}=0.02)$.

Doctors in the Emergency Department and those in the field of paediatrics scored higher than the other specialties. ED total scores were 81.3 (95\% Cl 77.5- 85.1). The paediatric scores were all high (as one would expect) with a total score of $85.7(95 \% \mathrm{Cl} 78.3-93.1)$. It was interesting to note that the paediatric trainees had higher scores, albeit not significantly, $(92.695 \% \mathrm{Cl} 85.2-100.0)$ when compared with the paediatric consultants (total score $87.795 \% \mathrm{Cl}$ 77.9-97.5). Scores for ICU/Anaesthetics (grouped together) were lower with a mean total score of $62.3(95 \% \mathrm{Cl} 59.9-74.7)$ and the surgical specialties had mean total scores of $53.5(95 \% \mathrm{Cl} 44.9-62.1)$

A subgroup analysis was done which compared doctors working in the Emergency Department to the other groups together (ie Paediatrics, ICU, Anaesthetics and Surgery). This showed that ED doctors performed at a higher level compared to the other groups in all scores. The ED total score was significantly higher than the other groups $(81.395 \% \mathrm{Cl} 77.5-85.1$ vs $61.395 \% \mathrm{Cl} 54.7-67.9 \mathrm{P}<0.001)$ as well as the calculation score $(71.595 \% \mathrm{Cl} 65.9-77.1$ vs $56.295 \% \mathrm{Cl} 47.4-65.0 \mathrm{P}<0.001)$ and fluid score (77.2 $95 \% \mathrm{Cl} 70.4-84.0$ vs $41.695 \% \mathrm{Cl} 33.6-49.6 \mathrm{P}<0.001)$.

Doctors who had received some formal education or ongoing tuition in the prescription of paediatric intravenous fluids not only felt more equipped to carry out the task but they also scored significantly higher on their Fluid scores $(72.195 \% \mathrm{Cl} 62.3-81.9$ vs $54.795 \% \mathrm{Cl} 50.7-58.7)$ and Total scores.

There was no statistical difference in any of the results when comparing doctors who checked their calculations against those that did not.

The results also indicate that doctors that prescribe intravenous fluids on a more frequent basis (at least weekly) had significantly better results in all their scores. (see table 6)

Doctors who had completed the APLS and PLS courses scored consistently higher than those doctors who had not completed theses courses.

\section{DISCUSSION}

This is the peer reviewed version of the following article: Keijzers, G., McGrath, M., \& Bell, C. (2012).

Survey of paediatric intravenous fluid prescription: Are we safe in what we know and what we do?

EMA - Emergency Medicine Australasia, 24(1), 86-97, which has been published in final form at https://doi.org/10.1111/j.1742-6723.2011.01503.x. This article may be used for non-commercial purposes in accordance with Wiley Terms and Conditions for Use of Self-Archived Versions 
This study aimed to observe the prescribing capabilities of a group of doctors in regards to paediatric intravenous fluids. It wanted to identify if doctors had a particular method for calculation of bolus and maintenance fluids and to investigate the types of fluids they are prescribing given the abundance of fluid types available in our hospitals. It also aimed to examine whether there was an awareness of the possibility of iatrogenic hyponatraemia and if this was considered in their fluid prescriptions. It was envisaged the study would identify if there was a need for further education for doctors in this area so as to ensure that our fluid prescriptions for children are accurate, consistent and above all, safe.

This study showed that a doctor's ability to correctly prescribe paediatric intravenous fluids increases with their medical experience and that in our institution doctors working in the fields of Paediatrics and Emergency Medicine are most capable of performing this task. This in itself is not surprising given that this population of doctors have greater amounts of experience in dealing with children and their specific illnesses. It was interesting to note that the doctors working in the areas of anaesthetics and ICU were less confident in their prescribing abilities and had lower Total scores as compared with the other critical care field of emergency (anaesthetics/ICU 62.3 vs emergency $81.3 \%$ ). This may be attributed to the fact the Gold Coast Hospital is not a specialist paediatric facility, with no specific paediatric intensive care, and limited paediatric surgical services.

It showed that our junior doctors and those working in the surgical specialities felt (and were) the least well equipped to prescribe intravenous fluids which is concerning since often it is left up to this population of doctors to prescribe and reorder maintenance fluids, often in the perioperative period (eg. after hours).

It also showed that frequent prescribers of this medical therapy have a higher ability to do so in a correct manner. The study showed that doctors who have undergone some formal training in this area outperform those that have not. It also showed that doctors who checked their calculations (or claimed to do so in the questionnaire) did not perform any better than those who did not check their calculations.

Reassuringly the great majority ( $>90 \%$ ) of doctors had both a method of calculating a bolus and maintenance rate of fluids, but were shown to be poor in the calculation of a fluid deficit as reflected by the low scores in question 6 of the questionnaire ( $54.7 \%$ correct). This is of particular concern as the calculation (and assessment) of a fluid deficit is one of the cornerstones of intravenous fluid prescription, for children and adults alike. It is also a very common task that doctors need to be comfortable in carrying out.

A fluid deficit or deficit therapy is a method of replacing previous losses from the extracellular (ECF) and intracellular (ICF) fluid spaces. It is a slow form of fluid replacement therapy often calculated over several hours or even days depending on the severity of the dehydration and electrolyte derangements (18). Deficits can result from fasting, excessive gastrointestinal, renal or cutaneous losses, haemorrhage or third space losses. Experiments carried out in the 1930's demonstrated a redistribution of total body water following a change in ECF volume and composition. It showed that the resulting hyponatraemia and hypotonicity produced a loss in both ECF and ICF and hence replenishment of the ICF is also required to fully correct a deficit(19).

Maintenance therapy represents the fluids and electrolyte requirements needed by an average individual with a normal ICF and ECF to replace anticipated physiological losses from breathing, sweating and urinary output for the upcoming 24 hours. (20) This is usually calculated from the aforementioned formulae however there are several exceptions to maintenance therapy that one must keep in mind. Fluid requirements may need to increase in patients with high solute loads (eg diabetic ketoacidosis) or high

This is the peer reviewed version of the following article: Keijzers, G., McGrath, M., \& Bell, C. (2012).

Survey of paediatric intravenous fluid prescription: Are we safe in what we know and what we do? 
protein losses (burns or crush injuries) or in simple situations such as a high fever or an increased respiratory rate. Similarly fluid therapy may need to be decreased in some situations especially when there may be excess ADH secretion (see Table 2). Excess ADH secretion can be overlooked in altering fluid prescriptions which can have potentially catastrophic repercussions. Moritz and Ayus(1) have detailed $>50$ cases of hospital acquired hyoponatraemia in children receiving hypotonic fluids. In this series there were 26 deaths. Tragically most of the deceased were otherwise healthy children undergoing minor surgery or suffering from common childhood illnesses.

Hyponatraemia can develop due to three main factors: excessive water ingestion, hypertonic urinary losses (rare, usually due to idiosyncratic reactions from thiazide diuretics) and the impaired ability to excrete free water. The most common cause of hospital acquired hyponatraemia is from this impaired ability of the kidney to excrete free water. This is directly due to the fact that excess ADH will increase the permeability of the collecting duct to water, leading to retention of free water(14). Hence children that receive hypotonic fluids with clinical states that increase $A D H$ secretion will become hyponatraemic(12).

Question 9 of the questionnaire referred to a 3 month old baby with meningitis. It was hoped that the respondents would consider the possibility of excess ADH secretion and the development of hyponatraemia in this situation, and to tailor their fluid prescription accordingly. However this question was answered poorly with only a $17.9 \%$ correct response rate for fluid rate and a $36.8 \%$ correct response rate for fluid choice. Even more concerning is the fact that $61.3 \%$ of our sample overestimated their fluid rate. This highlights that our convenience sample, despite having very good overall knowledge scores still have difficulty in applying this knowledge to their fluid prescriptions. Similarly there were poor results in the fluid choice in question 7 . This referred to a 9 month old baby with a SDH who was being fluid restricted (so as to account for an increase in $\mathrm{ADH}$ ). Only $34.9 \%$ of the respondents were correct in their choice of fluid with the majority of doctors choosing a hypotonic solution. The researchers believe this is a very important finding as the administration of excessive fluids or hypotonic fluids as was found from these questions will likely have significant morbidity and mortality as outlined above and hence may endanger our paediatric population.

What then is the ideal fluid solution? We know that children require glucose and sodium but in what proportions? Holliday and Segar proposed hypotonic solutions in their original dissertation and still advocate their use today albeit at a reduced maintenance rate (21). Moritz and Ayus are emphatic in their support for widespread use of an isotonic saline and $5 \%$ dextrose solution and assert that, "although no one fluid rate or composition will be appropriate for all children, isotonic saline and $5 \%$ dextrose in water seems to be the safest fluid composition in most hospitalized patients."

The use of isotonic solutions is gaining much support. In our Emergency Department there is only one specific fluid stored for paediatric use, namely NS and $5 \%$ dextrose. This may explain as to why Fluids scores were high in the Emergency Department doctors. Similarly after the questionnaires were circulated the use of hypotonic fluids has also been restricted in the general paediatric wards.

The researchers believe that the use of isotonic solutions would minimize the risk of iatrogenic hyponatraemia in a vulnerable population and that fluid delivery rates need to be carefully applied so as to avoid excess delivery of electrolyte free water.

\section{Study Limitations}

There were several limitations in this study. Firstly, it was performed at a single institution, limiting valid extrapolation to other sites, especially smaller hospitals or rural settings. There are also inherent selection biases that exist in any study population such as this, which results from a sample of convenience. Whilst

This is the peer reviewed version of the following article: Keijzers, G., McGrath, M., \& Bell, C. (2012).

Survey of paediatric intravenous fluid prescription: Are we safe in what we know and what we do?

EMA - Emergency Medicine Australasia, 24(1), 86-97, which has been published in final form at https://doi.org/10.1111/j.1742-6723.2011.01503.x. This article may be used for non-commercial purposes in accordance with Wiley Terms and Conditions for Use of Self-Archived Versions 
the study population is believed to be representative of all critical care, paediatric and surgical specialities at Gold Coast Hospital, there may exist bias that has not been recognised or corrected for which has affected the results. Similarly, we cannot exclude that the results are due to unmeasured variables and correcting for these potential confounders was beyond the scope of this descriptive study.

Secondly there was an uneven spread of subjects' level of training. The largest group of respondents were interns. Although when surveyed they were in their $3^{\text {rd }}$ term many had not had the opportunity to complete a paediatric or emergency term which may have influenced the actual scores of this group. However, this is likely a true refelction of the workforce in the Gold Coast Hospital, and these same Interns will prescribe fluids on the wards in peri-operative settings.

Their inexperience and presumably poorer skill level may bias the results given the general trend of the least experienced performing the worst. However these doctors may need to complete fluid orders on overtime shifts or on relief terms and hence their overall poorer performance is concerning and may indicate that more education sessions or calculating tools are needed so as to assist this group of doctors.

The observational nature of the study utilising a sample of convenience may have allowed for further selection bias. Some subjects may not have participated once discovering the purpose of the study if they anticipated they would perform poorly. This "self de-selection" would bias towards improved actual scores. Attempts were made to reduce this effect by conducting the survey at random times and without participants' prior knowledge of the study's purpose.

The last section of the questionnaire asked some general knowledge concepts about hyponatraemia and the tonicity of fluid solutions. The format of this was multiple choice which may have allowed candidates to "guess" correct answers and overestimate actual knowledge and ability.

Finally the fluid types chosen as correct in the questionnaire and the justification for their use (see Table 5) may be construed as the subjective choice of the researchers. We have endeavoured to choose these fluids after taking into account the physiological needs of the children in the scenarios and to employ a certain degree of "common sense".

\section{Future Directions}

Intravenous fluid therapy is a medical prescription. As such it needs to be ordered with accuracy both in composition of fluid and fluid volumes. This study showed that the majority of the respondents lacked confidence_in their own prescribing ability. Questions concerning infants were answered poorly, both in fluid composition and volumes and calculating deficits was seen to be difficult.

This would indicate that greater education is needed in this area as well as simplifying and streamlining the amount of fluids available. Clinical policies and practice guidelines concerning paediatric intravenous fluid administration vary between institutions and between states and there are no universal prescribing guidelines per se. This can probably be attributed to the fact that the actual evidence to support isotonic solutions is scant. A Cochrane review found no evidence to support the use of isotonic solutions in the management of acute infections(15) as there have been no large random controlled trials (RCTs) to support its use. However to perform these would be unethical and it was suggested that in institutions where hypotonic fluid use is routine, a change of policy such that isotonic fluid would become the standard background intravenous fluid and to carefully audit the change. Although not as robust as a RCT, this would allow for a detailed before and after analysis.

This is the peer reviewed version of the following article: Keijzers, G., McGrath, M., \& Bell, C. (2012).

Survey of paediatric intravenous fluid prescription: Are we safe in what we know and what we do?

EMA - Emergency Medicine Australasia, 24(1), 86-97, which has been published in final form at https://doi.org/10.1111/j.1742-6723.2011.01503.x. This article may be used for non-commercial purposes in accordance with Wiley Terms and Conditions for Use of Self-Archived Versions 
Two Australian studies purport the use of isotonic solutions in Intensive Care patients and in those children suffering from gastroenteritis requiring intravenous fluids $(22,23)$. The latter study has translated into a generalised use of NS and 5\% dextrose solutions as treatment for gastroenteritis at the Sydney Children's Hospital in NSW.

Clearly more prospective studies are needed in this area especially with reference to the perioperative period where increased $\mathrm{ADH}$ secretion is paramount.

In March 2007 the NHS in the United Kingdom produced a series of patient alerts so as to minimize the risk of hyponatraemia in children. These included:

1. Removal of $0.18 \%$ Sodium Chloride and $4 \%$ dextrose from stock and general use in areas that treat children. These fluids should be restricted to critical care and specialist wards such as renal, liver and cardiac units.

2. Produce and disseminate guidelines for fluid management of paediatric patients.

3. Provide adequate training and supervision for all staff involved in prescribing, administering and monitoring of IV infusions for children.

4. Reinforce safer practice by reviewing and improving the design of IV fluid charts and fluid balance charts.

5. Promote reporting of hospital acquired hyponatraemia incidents via local reporting systems(24)

There is a need for universal guidelines in Australia so as to alleviate some of the confusion found with paediatric fluid prescriptions. Hypotonic solutions should be limited to specialist areas and solutions should be clearly labeled as to their tonicity.

Medical students and practicing doctors should be given more tuition in regards to prescribing habits and calculating tools need to be available in all areas that treat children so that the less experienced doctors can adequately prescribe and that the more senior doctors can check their prescriptions. An example of this type of tool is shown in Appendix B and has been designed by the Gold Coast Hospital Emergency department to assist in safe IV fluid prescribing.

\section{CONCLUSIONS}

This study has shown that doctors in our institution performed reasonably well in the calculation of bolus and maintenance fluids in children, but that the calculation of a fluid deficit was problematic. It also showed that the sample population had difficulty when prescribing for infants. It showed that doctors with more experience in dealing with the paediatric population outperform those with less experience and that junior doctors and those in the fields of anaesthetics, ICU and surgery felt ill equipped to prescribe these fluids and hence had lower prescribing scores.

This is the peer reviewed version of the following article: Keijzers, G., McGrath, M., \& Bell, C. (2012).

Survey of paediatric intravenous fluid prescription: Are we safe in what we know and what we do?

EMA - Emergency Medicine Australasia, 24(1), 86-97, which has been published in final form at https://doi.org/10.1111/j.1742-6723.2011.01503.x. This article may be used for non-commercial purposes in accordance with Wiley Terms and Conditions for Use of Self-Archived Versions 
It showed that overall knowledge about hyponatraemia and fluid tonicity was good but that translating this knowledge into practice was poor as illustrated by the low correct response rate in some of the questions.

\section{ACKNOWLEDGEMENTS}

\section{Emergency Departments in Southport and Robina and their staff}

\section{REFERENCES}

1. Moritz M, Ayus J. Prevention of hospital acquired hyponatraemia: a case for using isotonic saline. Pediatrics2003;111:227 -30.

2. Beck C. Hypotonic versus isotonic maintenance fluid therapy in hopsitalized children: a systematic review. Clinical Pediatrics2007;46:764-70.

3. Taylor D, Durward A. Pouring salt on troubled waters. Archives of Disease in Childhood2004;89:411 - 4

4. Hanna S, Tibby S, Durward A, Murdoch I. Incidence of hyponatraemia and hyponatraemic seizures in severe respiratory syncytial virus brochiolitis. Acta Paediatrica2003;92:430- 4.

5. Playfor S. Hypotonic intravenous solutions in children. Expert Opinion In Drug Safety2004;3:67-

73.

6. Neville K, Verge C, O'Meara M. High antidiuretic hormone levels and hyponatraemia in children with gastroenteritis. Pediatrics2005;116:1401- 7 .

7. Holliday M, Segar W. The maintenance need for water in parenteral fluid therapy. Pediatrics1957;19:823- 32.

8. Murat I, Dubois M. Perioperative fluid therapy in pediatrics. Pediatric Anasthesia2008;18:363- 70.

9. $\quad$ Chesney R. THe maintenance need for water in parenteral fluid therapy. Pediatrics1998;102:399-

400.

10. Arieff A, Ayus J, Fraser C. Hyponatremia and death or permanent brain damage in healthy children. BMJ1992;304(1):1218- 22

11. Halberthal M, Halperin M, Bohn D. Lesson of the week: acute hyponatraemia in children admitted to hospital: retrospective analysis of factors contributing to its development and resolution.

BMJ2001;322:780- 2.

12. Hoorn E, Geary D, Robb M, Halperin M, Bohn D. Acute Hyponatraemia Related to Intravenous fluid administration in hospitalized children: an observational study. Pediatrics2004;113:1279- 84.

13. Duke T, Molyneux E. Intravenous fluids for seriously ill children : time to reconsider. The Lancet2003;362:1320-3.

14. Moritz M, Ayus J. Hospital acquired hyponatraemia- why are hypotonic parenteral fluids still being used? Nature Clinical Practice Nephrology2007;3:374- 82.

15. Duke T, Mathur A, Kukuruzovic R, McGuigan M. Hypotonic vs isotonic saline solutions for

intravenous fluid management of acute infections. THe Cochrane Library2009(2):1- 10.

16. Davies P, Hall T, Ali T, Lakhoo K. Intravenous postoperative fluid prescriptions for children- a survey of practice. BMC Surgery2008;8:10- 4.

17. Way C, Dhamrait R, Wade A, Walker I. Paeroperative fluid therapy in children: a survey of current prescribing practice. British Journal of Anaesthesia2006;97(3):371- 9.

18. Friedman A. Pediatric hydration therapy : historical review and a new approach. Kidney International2005;67:380- 8.

19. Darrow D, Yannet $\mathrm{H}$. THe changes in the ditribution of body water accompanying increase and decrease in extracellular fluid electrolyte. Journal of Clinical Investigation1935;14:266- 75. 
20. Paut O, Lacroix F. Recent developments in the perioperative fluid management for the pediatric patient. Current Opinion in Anaesthesiology2006;19:268- 77.

21. Holliday M, Segar W, Friedman A. Reducing errors in fluid therapy management.

Pediatrics2003;111:424- 5.

22. Yung M, Keeley S. Randomised control trial of intravenous maintenance fluids. Journal of Paediatrics and Child Health2007;45:9- 14.

23. Neville K, Verge C, Rosenberg A, O'Meara M, Walker J. Isotonic is better than hypotonic saline for intravenous rehydration of children with gastroenteritis: a propsective randomised study. Archives of Disease in Childhood2006;91:226- 32.

24. Service NH. Patient Safety Alert- reducing the risk of hyponatraemia when administering intravenous infusions to children. 2007.

This is the peer reviewed version of the following article: Keijzers, G., McGrath, M., \& Bell, C. (2012).

Survey of paediatric intravenous fluid prescription: Are we safe in what we know and what we do? 
Table 3. Demographic variables and workplace behaviours for study population. $(\mathrm{N}=106)$

\begin{tabular}{|c|c|c|}
\hline & Frequency & Percentage of Total \\
\hline $\begin{array}{l}\text { Sex } \\
\text { Male } \\
\text { Female } \\
\text { Did not answer }\end{array}$ & $\begin{array}{c}55 \\
50 \\
1\end{array}$ & $\begin{array}{l}52.4 \\
47.6\end{array}$ \\
\hline $\begin{array}{l}\text { Level of Training } \\
\text { Intern } \\
\text { Junior House Officer } \\
\text { Senior House Officer } \\
\text { Registrar } \\
\text { Consultant }\end{array}$ & $\begin{array}{c}39 \\
6 \\
11 \\
31 \\
19\end{array}$ & $\begin{array}{c}36.8 \\
5.7 \\
10.4 \\
29.2 \\
17.9\end{array}$ \\
\hline $\begin{array}{l}\text { Seniority of Doctor } \\
\text { Junior ( } \leq 3 \text { years) } \\
\text { Senior ( }>3 \text { years) }\end{array}$ & $\begin{array}{l}54 \\
52\end{array}$ & $\begin{array}{l}50.9 \\
49.1\end{array}$ \\
\hline $\begin{array}{l}\text { Speciality } \\
\text { Emergency Medicine } \\
\text { Paediatrics } \\
\text { Anaesthetics } \\
\text { ICU } \\
\text { Surgery } \\
\text { Missing }\end{array}$ & $\begin{array}{r}57 \\
7 \\
9 \\
3 \\
27 \\
3\end{array}$ & $\begin{array}{l}55.3 \\
6.8 \\
8.7 \\
2.9 \\
26.2\end{array}$ \\
\hline $\begin{array}{l}\text { Paediatric Experience } \\
\text { At least some Paed experience } \\
\text { Medical School/ Mixed ED } \\
\text { Missing }\end{array}$ & $\begin{array}{c}46 \\
59 \\
1\end{array}$ & $\begin{array}{l}43.8 \\
56.2\end{array}$ \\
\hline $\begin{array}{l}\text { Acute Paediatric Life Support } \\
\text { Course } \\
\text { Yes } \\
\text { No }\end{array}$ & $\begin{array}{l}34 \\
72\end{array}$ & $\begin{array}{l}32.1 \\
67.9\end{array}$ \\
\hline $\begin{array}{l}\text { Paediatric Life Support Course } \\
\text { Yes } \\
\text { No } \\
\text { Missing }\end{array}$ & $\begin{array}{c}23 \\
82 \\
1\end{array}$ & $\begin{array}{l}21.9 \\
78.1\end{array}$ \\
\hline $\begin{array}{l}\text { Prescribing Frequency } \\
\text { Weekly } \\
\text { Less than weekly } \\
\text { Missing }\end{array}$ & $\begin{array}{c}50 \\
55 \\
1\end{array}$ & $\begin{array}{l}47.6 \\
52.4\end{array}$ \\
\hline
\end{tabular}

This is the peer reviewed version of the following article: Keijzers, G., McGrath, M., \& Bell, C. (2012).

Survey of paediatric intravenous fluid prescription: Are we safe in what we know and what we do? 


\begin{tabular}{|l|c|c|}
\hline Formal Testing & 34 & 33.0 \\
Yes & 69 & 67.0 \\
No & 3 & \\
Missing & 94 & \\
\hline Check Fluid Calculations & 11 & \\
Always/ Mostly & 1 & \\
Sometimes/ Hardly/ Never & & \\
Missing & & \\
& & \\
& & \\
& & \\
\hline
\end{tabular}

Table 4: Fluid Calculation Test and answers and percentage of doctors who answered correctly

\begin{tabular}{|c|c|c|c|}
\hline Question & $\begin{array}{l}\text { Answer } \\
\text { (+/- 10\% for } \\
\text { calculations) }\end{array}$ & $\begin{array}{l}\text { Answer } \\
\text { Fluid choice }\end{array}$ & $\begin{array}{l}\text { \%Correct } \\
(n=106)\end{array}$ \\
\hline $\begin{array}{l}\text { 1.An } 8 \text { year old boy weighing } 25 \mathrm{~kg} \text { has distal radius and } \\
\text { ulna\# } \\
\text { Requires IV maintenance fluids overnight until OT } \\
\text { What is his hourly maintenance fluid rate? } \\
\text { 2.A } 3 \text { year old girl weighing } 14 \mathrm{~kg} \text { is awaiting elective } \\
\text { tonsillectomy. }\end{array}$ & $65 \mathrm{ml} / \mathrm{hr}$ & $\mathrm{NS}+5 \% \mathrm{D} / \mathrm{NS}$ & 85.8 \\
\hline $\begin{array}{l}\text { Requires maintenance fluids. } \\
\text { What is her fluid requirement per hour? } \\
\text { 3.A } 10 \text { year old boy weighing } 30 \mathrm{~kg} \text { is admitted to the ED } \\
\text { after being } \\
\text { Struck by a car. He is in hypovolaemic shock and requires a }\end{array}$ & $\begin{array}{c}48 \mathrm{ml} / \mathrm{hr} \\
300-600 \mathrm{ml}\end{array}$ & $\mathrm{NS}+5 \% \mathrm{D} / \mathrm{N} / 2$ & 80.2 \\
\hline
\end{tabular}

This is the peer reviewed version of the following article: Keijzers, G., McGrath, M., \& Bell, C. (2012).

Survey of paediatric intravenous fluid prescription: Are we safe in what we know and what we do? 


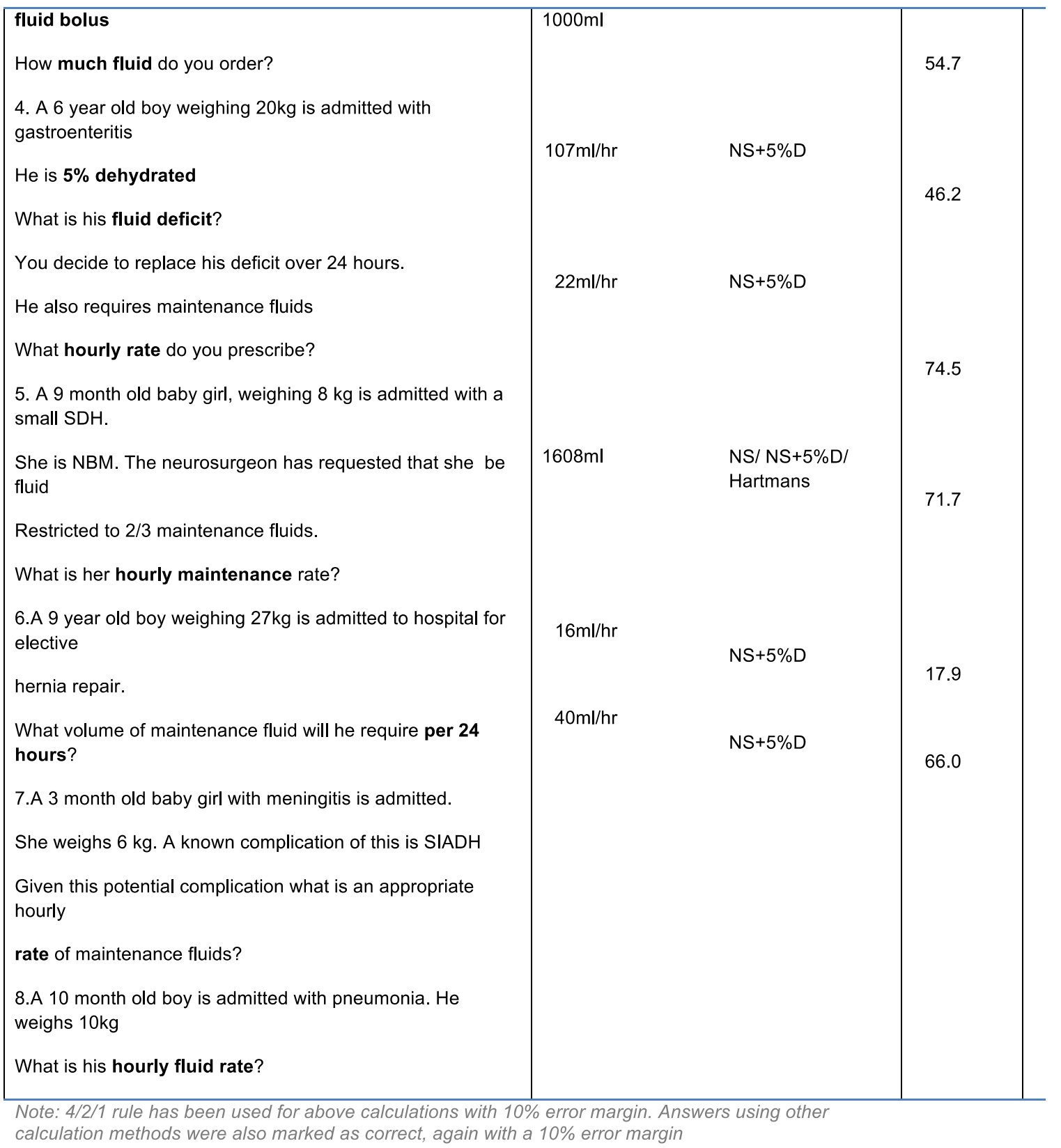

This is the peer reviewed version of the following article: Keijzers, G., McGrath, M., \& Bell, C. (2012).

Survey of paediatric intravenous fluid prescription: Are we safe in what we know and what we do? 
Table 5:Fluid choices for questionnaire scenarios

\begin{tabular}{|c|c|c|}
\hline Question & Fluid Type & Why \\
\hline $\begin{array}{r}1.8 \text { year old } \\
\text { Pre op }\end{array}$ & $\begin{array}{l}\text { Normal Saline(NS) }+5 \% \\
\text { Dextrose, NS, NS + } \\
20 \text { mmolKCL } \\
\text { Hartmanns }\end{array}$ & $\begin{array}{l}\text { Has the ability to fast but requires } \\
\text { isotonic fluids as at risk of increased } \\
\text { ADH due to pain }\end{array}$ \\
\hline 2.3 year old girl & $\begin{array}{l}\text { NS }+5 \% \text { (most } \\
\text { appropriate) } \\
0.45 \% \text { NS }+2.5 \% \\
\text { Dextrose }\end{array}$ & $\begin{array}{l}\text { She has a limited ability to fast. Post } \\
\text { op children at risk of hyponatraemia } \\
\text { hence should have isotonic fluid }\end{array}$ \\
\hline 3. 10 year old boy & NS or Hartmans & $\begin{array}{l}\text { Haemodynamically unstable } \\
\text { Needs isotonic fluid }\end{array}$ \\
\hline $\begin{array}{l}4.6 \text { year old boy } \\
\text { with gastro and } 5 \% \\
\text { dry }\end{array}$ & NS $+5 \%$ Dextrose & $\begin{array}{l}\text { Needs isotonic fluid to replace deficit } \\
\text { and glucose as likely ketotic }\end{array}$ \\
\hline $\begin{array}{l}5.9 \text { month old baby } \\
\text { with SDH }\end{array}$ & NS $+5 \%$ Dextrose & $\begin{array}{l}\text { Increased risk of SIADH hence should } \\
\text { not have a hypotonic solution, will } \\
\text { also require dextrose }\end{array}$ \\
\hline $\begin{array}{l}6.9 \text { year old boy } \\
\text { periop }\end{array}$ & $\begin{array}{l}\text { NS, NS+5\% Dextrose or } \\
\text { Hartmans }\end{array}$ & $\begin{array}{l}\text { Has the ability to fast but may have } \\
\text { increased SIADH due to pain and } \\
\text { post op hence should have an } \\
\text { isotonic solution }\end{array}$ \\
\hline $\begin{array}{l}7.3 \text { month old baby } \\
\text { with meningitis }\end{array}$ & $\mathrm{NS}+5 \%$ dextrose & $\begin{array}{l}\text { Risk of SIADH } \\
\text { Needs isotonic fluid and dextrose }\end{array}$ \\
\hline 8.10 month old & $\mathrm{NS}+5 \%$ & Risk of SIADH \\
\hline
\end{tabular}

This is the peer reviewed version of the following article: Keijzers, G., McGrath, M., \& Bell, C. (2012).

Survey of paediatric intravenous fluid prescription: Are we safe in what we know and what we do? 
Table 6 Mean percentage scores with 95\% Confidence Intervals for subgroups in relation to their perceived adequacy of training, calculation, fluid, knowledge and total scores

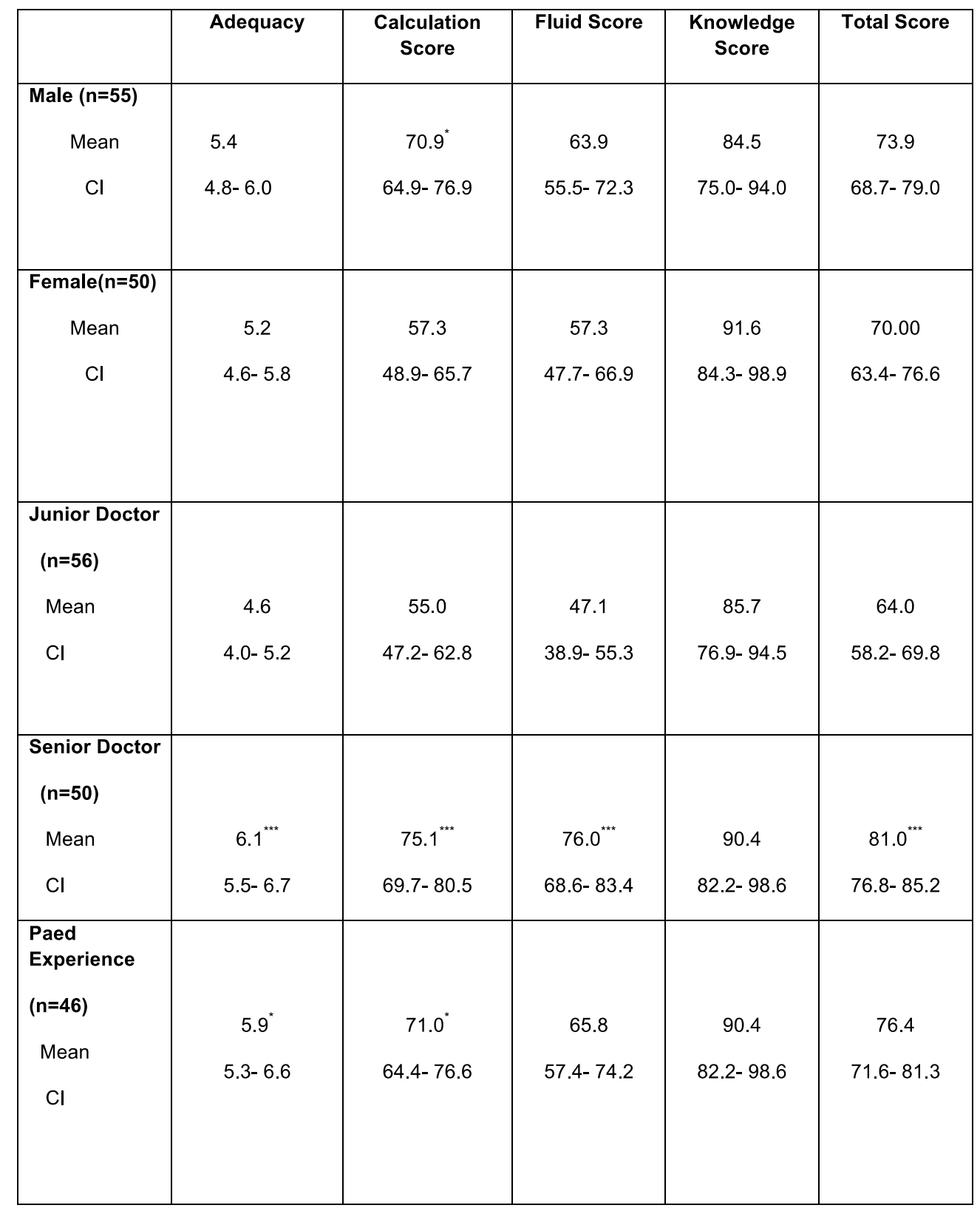

This is the peer reviewed version of the following article: Keijzers, G., McGrath, M., \& Bell, C. (2012).

Survey of paediatric intravenous fluid prescription: Are we safe in what we know and what we do? 


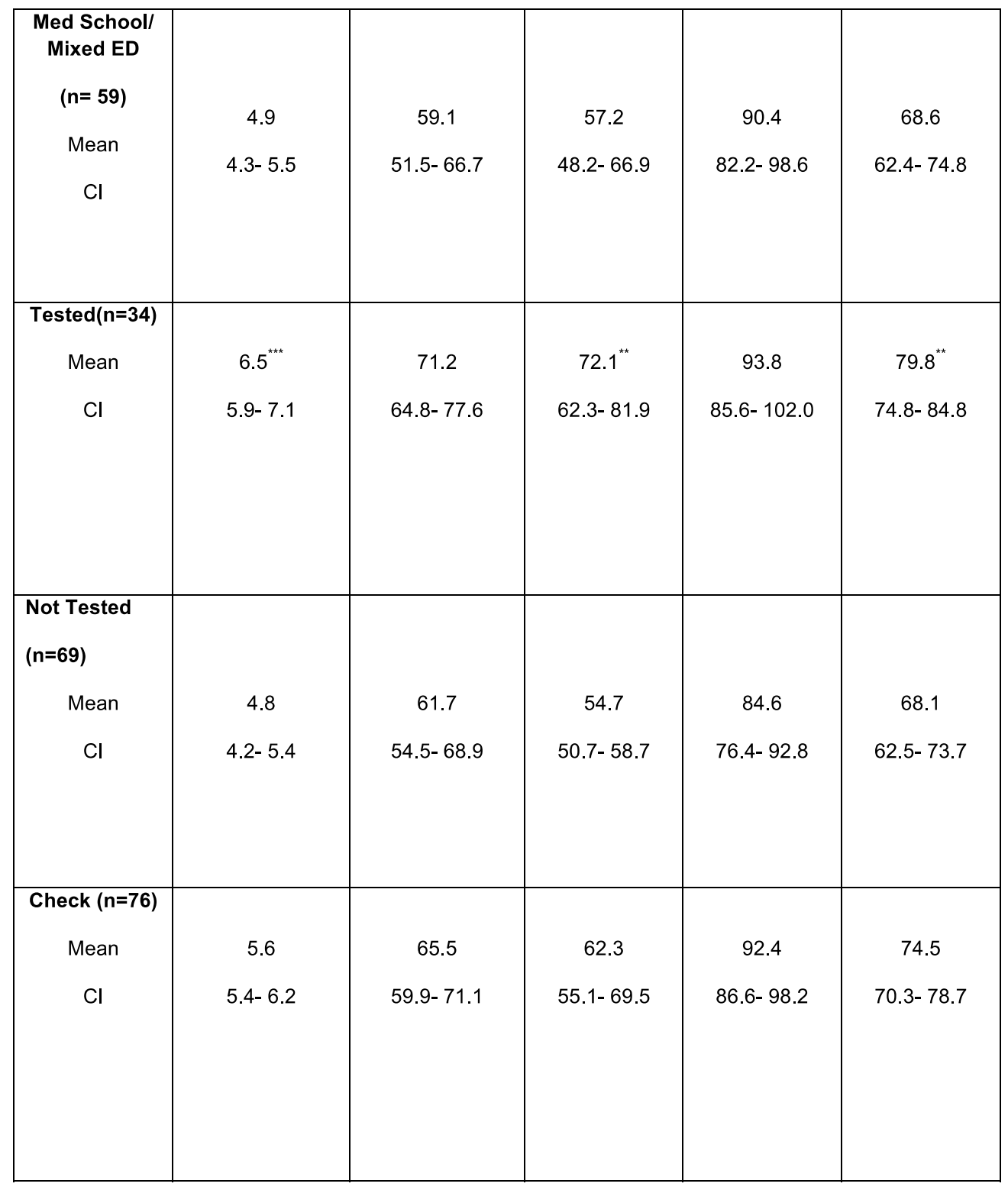

This is the peer reviewed version of the following article: Keijzers, G., McGrath, M., \& Bell, C. (2012).

Survey of paediatric intravenous fluid prescription: Are we safe in what we know and what we do? 


\begin{tabular}{|c|c|c|c|c|c|}
\hline \multicolumn{6}{|l|}{$\begin{array}{l}\text { No Check } \\
(n=29)\end{array}$} \\
\hline Mean & 4.6 & 64.0 & 58.2 & 79.3 & 67.9 \\
\hline $\mathrm{Cl}$ & $4.0-5.2$ & $52.8-75.2$ & $45.6-70.8$ & $65.1-93.5$ & $59.3-75.5$ \\
\hline \multicolumn{6}{|l|}{$\begin{array}{l}\text { Weekly } \\
(n=50)\end{array}$} \\
\hline Mean & $6.4^{* * *}$ & $76.7^{* \star *}$ & $75.5^{\star \star \star *}$ & 90.4 & $81.4^{\star \star \star}$ \\
\hline $\mathrm{Cl}$ & $6.0-6.8$ & $71.5-81.9$ & $67.9-83.1$ & $82.2-98.6$ & $77.0-85.8$ \\
\hline \multicolumn{6}{|c|}{$\begin{array}{c}<\text { Weekly } \\
(n=55)\end{array}$} \\
\hline Mean & 4.3 & 53.3 & 47.3 & 85.6 & 63.5 \\
\hline $\mathrm{Cl}$ & $3.7-4.9$ & $45.5-61.1$ & $38.8-55.6$ & $76.6-94.6$ & $57.5-69.5$ \\
\hline
\end{tabular}

This is the peer reviewed version of the following article: Keijzers, G., McGrath, M., \& Bell, C. (2012).

Survey of paediatric intravenous fluid prescription: Are we safe in what we know and what we do? 
Table 7: Summary of scores according to speciality

\begin{tabular}{|c|c|c|c|c|c|}
\hline Speciality & Adequacy & $\begin{array}{l}\text { Calculation } \\
\text { Score }\end{array}$ & Fluid Score & $\begin{array}{l}\text { Knowledge } \\
\text { Score }\end{array}$ & Total Score \\
\hline ED & 5.6 & & & & \\
\hline Mean & $5.0-6.2$ & 71.5 & 77.2 & 93.3 & 81.3 \\
\hline $\mathrm{Cl}$ & & 65.9- 77.1 & $70.4-84.0$ & 86.9- 99.7 & 77.5- 85.1 \\
\hline \multicolumn{6}{|l|}{ Paediatrics } \\
\hline Mean & 7.4 & 84.1 & 80.6 & 91.4 & 85.7 \\
\hline $\mathrm{Cl}$ & $6.0-8.8$ & 75.9- 92.3 & $73.2-88.0$ & $74.2-108.6$ & 78.3- 93.1 \\
\hline \multirow{2}{*}{\multicolumn{6}{|c|}{$\begin{array}{c}\text { ICU/ } \\
\text { Anaesthetics }\end{array}$}} \\
\hline & & & & & \\
\hline Mean & 4.5 & 63.9 & 41.7 & 77.5 & 62.3 \\
\hline $\mathrm{Cl}$ & 3.3- 5.7 & $46.3-81.5$ & $28.1-55.3$ & $53.7-101.3$ & 59.9- 74.7 \\
\hline \multicolumn{6}{|l|}{ Surgery } \\
\hline Mean & 4.5 & 43.6 & 32.4 & 79.3 & 53.5 \\
\hline $\mathrm{Cl}$ & $3.7-5.3$ & $32.4-54.8$ & $22.6-42.2$ & $64.1-94.5$ & $44.9-62.1$ \\
\hline
\end{tabular}

This is the peer reviewed version of the following article: Keijzers, G., McGrath, M., \& Bell, C. (2012).

Survey of paediatric intravenous fluid prescription: Are we safe in what we know and what we do? 


\section{APPENDIX A:}

Questionnaire Tool

\section{Dear Colleagues,}

Thank you for choosing to participate in this project. This survey is being carried out by Doctors Melissa McGrath, Christa Bell and Gerben Keijzers and is a major component of a research project being completed as part of the Australasian College of Emergency Medicine training.

This project aims to look at how doctors in our hospital prescribe paediatric intravenous fluids. We want to see if there is a pattern of uniformity in the type of paediatric IV fluid prescribed, if people feel comfortable with calculating fluid rates and whether there is a need for more education in this area, especially for doctors that may not prescribe these fluids on a regular basis.

We appreciate your time and effort in completing this questionnaire. It should take about 15-20 minutes. You are permitted to use a calculator if you wish to. The questionnaire and its results are completely anonymous. There is no way to identify the respondents on the form and this information is purely for the purposes of research.

All the results will be statistically analysed and presented as a written document and oral presentation later in the year. The results will be stored in secure computer files and locked cabinets, accessed only by the investigators and retained for a period of 7 years prior to being destroyed.

Please try and complete all the questions.

Thank you once again for your time and contribution to this project.

This is the peer reviewed version of the following article: Keijzers, G., McGrath, M., \& Bell, C. (2012).

Survey of paediatric intravenous fluid prescription: Are we safe in what we know and what we do? 


\section{Section A}

1. Please circle your sex:
a. Female

b. Male

2. Please circle your current level of training:
a. Intern
b. Junior House Officer
c. Senior House Officer
d. Registrar/ Principal House Officer
e. Consultant

3. Please circle your specialty or current department
a. Emergency
b. Paediatrics
c. Anaesthetics
d. Intensive Care
e. Surgery (including sub specialities)

4. How many years have you practiced medicine? Please estimate to the nearest half year. E.g. 2.5 years

years

5. What experience in Paediatrics have you had?
a. Paediatric Consultant
b. Paediatric Trainee
c. 6 month term (general or PICU)
d. $<6$ month term
e. Mixed/ paediatric ED
f. Medical School

6. Have you completed the APLS course? (Advanced Paediatric Life Support)
a. Yes
b. No

This is the peer reviewed version of the following article: Keijzers, G., McGrath, M., \& Bell, C. (2012).

Survey of paediatric intravenous fluid prescription: Are we safe in what we know and what we do? 
7. Have you completed the PLS course? (Paediatric Life Support)

a. Yes

b. No

8. How often would you need to prescribe paediatric intravenous (IV) fluids?

a. Twice or more per day

b. Daily

c. Weekly

d. Monthly

e. Never

9. Please circle how often you are formally tested or have compulsory continuing education tasks (e.g. college training programs) to complete regarding paediatric IV fluids prescription?

a. Yearly

b. At least once during my specialty training

c. Never

10. When prescribing paediatric IV fluids (bolus or maintenance) do you double check your fluid rates?

a. Always

b. Most of the time

c. Sometimes

d. Hardly ever

e. Never

11. Please mark with an arrow on the scale below, how adequate you feel your teaching and training has been regarding the practical skill of paediatric IV fluid prescription.

None $\quad$ Poor Average Good Excellent

This is the peer reviewed version of the following article: Keijzers, G., McGrath, M., \& Bell, C. (2012).

Survey of paediatric intravenous fluid prescription: Are we safe in what we know and what we do? 


\section{Section B}

In the Gold Coast Hospital the following fluids are available:

$0.9 \%$ Saline (Normal Saline)

$0.9 \%$ Saline/ $5 \%$ Dextrose

Hartmann's solution

$0.18 \%$ Saline/ 4\% Dextrose (N/4)

$0.3 \%$ Saline/ 3\% Dextrose (N/3)

$0.45 \%$ Saline/ $2.5 \%$ Dextrose (N/2)

$5 \%$ Dextrose

$10 \%$ Dextrose

$0.9 \%$ Saline/ $20 \mathrm{mmol} \mathrm{KCl}$

$0.9 \%$ Saline/ $40 \mathrm{mmol} \mathrm{KCl}$

1. Do you use a particular formula or approach when calculating bolus fluids?

$\square$ No

$\square$ Yes, namely

$10 \mathrm{ml} / \mathrm{kg}$ or $20 \mathrm{ml} / \mathrm{kg}$

2. Do you use a particular formula or approach when calculating maintenance fluids?

$\square$ No

$\square$ Yes, namely

4/2/1 rule (used for following calculations)

$100 \mathrm{ml} / \mathrm{kg}(<10 \mathrm{~kg}), 1000 \mathrm{ml}+50 \mathrm{ml} / \mathrm{kg}(10$ to $20 \mathrm{~kg}), 1500 \mathrm{ml}+25 \mathrm{ml} / \mathrm{kg}(>20 \mathrm{~kg})$ (if using

this method scores will be slightly different but have been marked as

correct)

3. An 8 year old boy, weighing $25 \mathrm{~kg}$ is admitted via the Emergency Department with fractures of his distal radius and ulna. He will require manipulation in the operating theatre the following morning. He requires IV maintenance fluids overnight.

a. What is his maintenance fluid requirement per hour?

65

Correct $85.8 \%$

Incorrect $14.2 \%$

This is the peer reviewed version of the following article: Keijzers, G., McGrath, M., \& Bell, C. (2012).

Survey of paediatric intravenous fluid prescription: Are we safe in what we know and what we do? 
b. What IV fluid is the most appropriate to prescribe?

4. A 3 year old girl weighing $14 \mathrm{~kg}$ is awaiting elective tonsillectomy. She is the last patient on an all day list. The anaesthetist has asked you to write her up for some IV maintenance fluids.

a. What is her fluid requirement per hour?

48

Correct $80.2 \%$

Incorrect $19.8 \%$

b. What IV fluid is the most appropriate to prescribe?

5. A 10 year old boy, weighing $30 \mathrm{~kg}$, is admitted to the Emergency Department having been knocked down by a car. He has multiple fractures and is haemodynamically unstable with tachycardia and prolonged capillary refill. He requires a fluid bolus to help restore his circulatory volume.

a. How much fluid do you order as a bolus?

$\simeq_{600 \_} \mathrm{ml}$

Correct $83.0 \%$

Incorrecct $17.0 \%$

b. What IV fluid is the most appropriate to prescribe?

6. A 6 year old boy weighing $20 \mathrm{~kg}$ with no significant past history is admitted with a 48 hour history of gastroenteritis. Following clinical examination he is estimated to be $5 \%$ dehydrated.

a. What is his fluid deficit?

${ }^{1000 \_} \mathrm{ml}$

Correct $54.7 \%$

Incorrect $45.3 \%$

This is the peer reviewed version of the following article: Keijzers, G., McGrath, M., \& Bell, C. (2012).

Survey of paediatric intravenous fluid prescription: Are we safe in what we know and what we do?

EMA - Emergency Medicine Australasia, 24(1), 86-97, which has been published in final form at https://doi.org/10.1111/j.1742-6723.2011.01503.x. This article may be used for non-commercial purposes in accordance with Wiley Terms and Conditions for Use of Self-Archived Versions 
b. You decide to replace his fluid deficit over 24 hours. He will also need maintenance fluids. What hourly rate do you prescribe?

$107 \_\mathrm{ml} / \mathrm{hr}$

Correct $46.2 \%$

Incorrect 53.8\%

c. What IV fluid is the most appropriate to prescribe?

7. A 9 month old baby girl, weighing $8 \mathrm{~kg}$ is admitted to the neurosurgical ward with a small SDH which is going to be managed conservatively. The baby is to be kept NBM and the neurosurgeon has requested that she be restricted to $2 / 3$ normal maintenance fluids.

a. What is her hourly intravenous fluid maintenance rate?

${ }_{2}^{22} \mathrm{ml} / \mathrm{hr}$

Correct $74.5 \%$

Incorrect $25.5 \%$

b. What IV fluid is the most appropriate to prescribe?

8. A 9 year old boy weighing $27 \mathrm{~kg}$ is admitted to hospital for an elective hernia repair.

a. What volume of maintenance fluids should you prescribe over $\mathbf{2 4}$ hours?

1608 $m l$

Correct $71.7 \%$

Incorrect $28.3 \%$

b. What IV fluid is the most appropriate to prescribe?

9. You admit a 3 month old baby girl weighing $6 \mathrm{~kg}$ with a diagnosis of bacterial meningitis. She is haemodynamically stable. A known complication of this is SIADH.

a. Given this potential complication what is an appropriate hourly rate of maintenance fluids?

$-16 \_\mathrm{ml} / \mathrm{hr}$

This is the peer reviewed version of the following article: Keijzers, G., McGrath, M., \& Bell, C. (2012).

Survey of paediatric intravenous fluid prescription: Are we safe in what we know and what we do?

EMA - Emergency Medicine Australasia, 24(1), 86-97, which has been published in final form at https://doi.org/10.1111/j.1742-6723.2011.01503.x. This article may be used for non-commercial purposes in accordance with Wiley Terms and Conditions for Use of Self-Archived Versions 
Correct $17.9 \%$

Incorrect $82.1 \%$

b. What IV fluid is the most appropriate to prescribe?

10. A 10 month old boy is admitted with high fevers and a cough. CXR reveals an area of consolidation. He is commenced on IV antibiotics. He also requires maintenance fluids. $\mathrm{He}$ weighs $10 \mathrm{~kg}$.

a. What is his hourly IV fluid rate?

$40 \_\mathrm{ml} / \mathrm{hr}$

Correct $66 \%$

Incorrect $34 \%$

c. What IV fluid is the most appropriate to prescribe?

This is the peer reviewed version of the following article: Keijzers, G., McGrath, M., \& Bell, C. (2012).

Survey of paediatric intravenous fluid prescription: Are we safe in what we know and what we do?

EMA - Emergency Medicine Australasia, 24(1), 86-97, which has been published in final form at https://doi.org/10.1111/j.1742-6723.2011.01503.x. This article may be used for non-commercial purposes in accordance with Wiley Terms and Conditions for Use of Self-Archived Versions 


\section{Section C}

Please circle the response that you think is most appropriate for the question.

1. Which one of the following groups of children is at most risk of developing acute symptomatic hyponatraemia whilst in hospital?

A. Children administered $0.9 \%$ Saline/ $5 \%$ dextrose at normal maintenance rates

B. Children administered oral fluids at standard maintenance rates

c. Critically ill children admitted to paediatric intensive care units

D. Previously well children admitted for elective surgery and administered hypotonic IV fluids

E. Children who have received $20 \mathrm{ml} / \mathrm{kg}$ of $0.9 \%$ Saline as a bolus

2. Which of the following statements about monitoring children receiving IV fluids is correct?

A. You should measure plasma electrolytes every 24 hours while IV fluids are being administrated

B. Weighing children is rarely helpful

c. You should measure all serum electrolytes before all elective surgery

D. It is easy to document accurate fluid balances in most paediatric patients

E. Intravenous fluid orders should be prescribed per 24 hour period

3. Children in the postoperative state receiving hypotonic IV fluids may develop acute symptomatic hyponatraemia. Which of the following is a common presenting feature of this problem?

A. Headache

B. Abdominal pain

c. Polyuria

D. Hypothermia

E. Hyperthermia

4. A 15 year old boy weighing $70 \mathrm{~kg}$ is recovering from a laparotomy and has ongoing fluid loss from a surgical wound drain. Which one of the following statements about prescribing intravenous fluids to this patient is most correct?

A. You should meet his maintenance fluid requirement with $0.45 \%$ Saline/ $2.5 \%$ Dextrose

B. You should assess ongoing fluid loses every 4 hours

This is the peer reviewed version of the following article: Keijzers, G., McGrath, M., \& Bell, C. (2012).

Survey of paediatric intravenous fluid prescription: Are we safe in what we know and what we do? 
c. Ongoing fluid losses are best replaced with $5 \%$ Dextrose

D. Ongoing fluid losses are best replaced with $0.18 \%$ Saline / $4 \%$ Dextrose

E. His daily IV fluid requirement is $3500 \mathrm{ml}$

5. A range of IV fluids is available in our hospital for children. Please indicate whether the following fluids are isotonic, hypotonic or hypertonic with reference to the cell membrane?

A. $10 \%$ Dextrose
$\square$ hypotonic $\square$ isotonic
B. $0.9 \%$ Saline/ $5 \%$ Dextrose
$\square$ hypotonic $\square$ isotonic $\square$ hypertonic
c. $\quad 0.45 \%$ Saline/ $2.5 \%$ Dextrose
$\square$ hypotonic $\square$ isotonic $\square$ hypertonic
D. $0.18 \%$ Saline/ $4 \%$ Dextrose
$\square$ hypotonic $\square$ isotonic $\square$ hypertonic
E. $0.3 \%$ Saline/ $3 \%$ Dextrose
$\square$ hypotonic $\square$ isotonic $\square$ hypertonic
F. $0.9 \%$ Saline
$\square$ hypotonic $\square$ isotonic $\square$ hypertonic

The questionnaire is now finished. Thank you!!!

This is the peer reviewed version of the following article: Keijzers, G., McGrath, M., \& Bell, C. (2012).

Survey of paediatric intravenous fluid prescription: Are we safe in what we know and what we do? 


\section{Appendix B}

This is the peer reviewed version of the following article: Keijzers, G., McGrath, M., \& Bell, C. (2012).

Survey of paediatric intravenous fluid prescription: Are we safe in what we know and what we do? 